\title{
Social Mission of Students in the Educational Process: The Past and the Present
}

\author{
Maksymovska Nataliia Oleksandrivna
}

Doctor of Pedagogical Sciences

Kharkiv State Academy of Culture,

Kharkiv, Ukraine

\section{Shepelieva Nataliia Viacheslavivna}

\author{
Postgraduate Student, \\ Kharkiv State Academy of Culture, \\ Kharkiv, Ukraine
}

Doi: 10.2478/jesr-2019-0019

\begin{abstract}
The article considers the interconnection between students' social mission in the conditions of information society and improvement of higher educational process. The aim and tasks of the article are to examine the dynamics of students' social mission, to study out the characteristic features of improving educational process in relation to contemporary tasks of training a competent professional, empiric verification of proposed scientific positions. To investigate the connection between students' social mission and optimization of educational process a set of methods was used: theoretical - historical analysis to define students' social mission; comparison, generalization of scientific facts to uncover contemporary interaction tendencies of students' social role and the flow of educational process; synthesis for clarification of the "students' social mission" concept; empiric - experimental research of students' satisfaction with the educational process, survey through online questionnaire, mathematic processing and generalization of acquired data. Analysis of open-type responses regarding the proposed remarks and recommendations enabled the formation of action directions to improve the conditions of educational process, such as support and facilitation of students' academic mobility, usage of new forms and means in educational process (distance learning, training, contemporary information technologies and others), correspondence of the contents of educative qualification study programs with contemporary demands of a job market and others. Results of this study will be useful for scholars of social pedagogy, teachers, methodologists and heads of higher educational institutions, social pedagogues, social workers, students, etc.
\end{abstract}

Keywords: students, educational process, higher educational institution, social mission, information society

\section{Introduction}

The higher educational system is at the peak of its reformation in information society and requires substantiation of effective pedagogical technologies for regulating the educational process and increasing the effectiveness of obtaining basic competencies by students as future professionals and social leaders. The process of changing the higher educational model mainly transmits knowledge and forms professional skills that accompanies students during self-dependent professional growth and obtaining social maturity. After many years of transformation, higher education has become a complex dynamic system that aims not only at ensuring the preparation of 
competitive specialists in various functioning fields of state and society, but also at setting improvement priorities for intellectuals of our time. Unlike the previous development stages, training of skilled workforce happens on the basis of several tasks that was formulated by contemporary challenges, particularly by the need to integrate national higher educational system into European and worldwide environment, functioning in the conditions of globalization changes, as well as tasks that the state solves in order to improve nation-level specialists training. At every age higher educational system reflects the state of socio-cultural environment and top social values, which changes the social mission of students, which in turn, increases the importance of systematic changes in general educational process of a higher educational institution, particularly, the organization of its educational process.

\section{Aim and Tasks}

Further scientific generalization requires, on the one hand, the growth of students' social role as future creative professionals in various fields of information age livelihood, and ,on the other hand, - related changes of foundation of higher educational institutions' educational activities. The aim of this article is to review the dynamics of students' social mission, to uncover the characteristic features of improving the process of teaching in relation to contemporary tasks of training a competent specialist. The tasks of the work are to study the harmonization of the future specialists' establishment process with an important social mission, as well as planning and conducting education at higher educational institutions, empirical verification of substantiated scientific propositions.

\section{Research Methodology}

The research was conducted using the sampling method. The sample amounted to 228 students of the $4^{\text {th }}$ year of Simon Kuznets Kharkiv National University of Economics. This is justified by the fact that bachelor graduates can adequately assess the quality of the educational process. The experiment consists in conducting an online survey that contains open and closed questions. For processing the results, a quantitative analysis method was used (for answering closed questions) and a content analysis method (for answering open questions). The data obtained were grouped, analyzed using the calculation of structural indicators and presented by a graphical method. Students' answers to open-ended questions allowed to identify shortcomings in the learning process and formulate recommendations for its improvement.

\section{Discussion}

As students' social mission demands investigation from both the pedagogical theory and practical implementation of points of view, we will generalize author's position in the frameworks of the definition. We generally consider that "a mission" is the leading aim, the purpose of being. However, defining "a social mission", nowadays, is debatable, thus, in order to deepen the understanding of the definition, we must determine its key traits and contents.

It would seem that the social mission of the subjects of higher education is related to the social responsibility of an educational institution. The essential part of university social responsibility within the concept of ESPRIT project is defined as "social responsibility of higher education related to institutions' and students' commitment to cooperate and contribute to the development of society, community within which a university acts, and includes measures and actions the university community takes in order to stay true to this commitment" (Orzhel, 2017, p. 6). It's worth noting however, that within the context of analyzing students' social mission university responsibility should be treated as a more general and broad concept.

Analysis of scientific research by the authors allows us to note that the contents of students' social mission include socio-professional realization and intellectual enlightenment focus (Drach, 2014); moral approach to profession and interaction with other people and environment (Vynoslavska, 2011), social mission realization criteria, in particular,which concerns charity 
projects, environment protection programs and support of social initiatives (Shevchuk, 2013), etc. Thus, social mission has its own structure and, in our opinion, consists of social subjectivity, social activeness and social responsibility of individual and group levels.

Subjectivity reflects the relation of man to himself as an acting agent, to other people and society in general, manifests itself in actions and is a quality of a mature person. Social subject constructs a value approach to important aspects of social life. Social subjectivity implies active, self-determined behavior of a person in various social systems, which displays itself in conscious choice of a certain type of social behavior regarding demands of a situation, norms and values.

Socially active position is inherent to the subject of social creativity and must define the basic parameters of inclusion into society, in particular - approach to other people, social groups, personal activities and activities of others, surrounding social environment of various levels of its organization (civic, ethnic, regional and global). Subject must be ahead in expanding socio-cultural environment, realize the responsibility and perspectives of their activities, have certain social experience, want new things, be ambitious, be prepared for transformations, express social initiative, critically evaluate social reality, not be indifferent and a mere consumer (Ferreira de Araújo et al., 2014).

As follows, social mission of students is a purposeful display of socially- professional and civilly directed maturity of this psycho-age group's members, which manifests itself in realization of social tendencies and issues of today, self-dependent definition of tasks that lead to positive changes which happen within a higher educational institution and social environment in general, as well as in choosing means of their completion and responsibility for the result of respective actions.

By relying on integrative totality of parameters - students' subject position which is based on psycho-age traits and features of group affiliation, this group's status in information of the society, features of main activity - we propose authorial typology of student youth's social mission manifestation: socially-creative type defined by a high level of self-recognition alongside with the understanding of the variety of social opportunities and societal issues, that consciously plans its own activities, taking into account pro-social value, makes like-minded individuals interested in personal position, unites others with common interest, evaluates situations critically, makes substantiated decisions, constructively interacts with various social groups, produces socially positive aims of activity, actively uses information environment resources and defines means of reaching goals; traditionally-executive type generally participates in social interaction, but proposes no initiatives, instead, supporting those that match its interests, approves solidarity within a group, works hard on what partakes in, enjoys group accomplishments and opportunities to demonstrate its own abilities; passively-unstable type has its own interest, but it never voices it, avoids extra attention and perform periodical tasks - sometimes splendidly, if it matches its abilities - if a group asks, never makes its own proposals, may reject interaction; consumer-destructive type is passive or extremely asocial, prone to constant criticism, consumerism dominates its behavior; it is also sometimes reclusive, excessively active towards ruining interaction, can hold on to unconstructive position and not coordinate its action with the group.

Thus, defining students' social mission and its typology allow us to make generalizations that will become the basis for viewing it as a factor of improving educational process on contemporary conditions.

Firstly, students' social mission is directly related to the mission of an educational institution, meaning what university's social mission and responsibility include, besides general educational process organization and management basics, such components as social mission of its subjects.

Secondly, students' social mission has its own structure and is based on person's social subjectivity, activeness and responsibility.

Thirdly, students' social mission must be considered one of the top priorities in the educational process within an institution during selection of modern educational methods and organization of extracurricular activities.

Historical examination will enable us to deepen the understanding of student youth's social mission dynamics. Emergence of first European universities during medieval times realized an important social task - preparing qualified clergy for social religious services. A university, essentially, was created as an organizational structure of a new society to gain charters, rights and 
privileges. According to Uvarov (2014), a European-type intellectual is not only a person that is mostly occupied with an intellectual labor, but is also obliged by a special social status to this exact activity. Society officially issued certificates of ability and right to work intellectually to the best members of youth, which is significant in our time as well. Hence, establishment of university-type higher educational institutions was the key event for training thinking professionals, which stimulated slow changes of both medieval thinking and intensification and demand for knowledge in later ages. Livelihood and behavior of future elite were supposed to match the dominant religious values of those times, which demanded that medieval students followed the virtuous social example and, simultaneously, caused the emergence of traditional teaching methods of those times (lectures and disputes). Thus, students' social mission of this period was to defend the ideas of Christianity, along with gaining professional basics and transmitting this behavior model into society.

During Renaissance, the development of philosophy, experimental sciences and typing promoted the blooming of university education. Professionalization of youth begins, not only as a philosopher or theologian, but also a professional in different fields of life (like natural sciences, medicine, etc.) must emerge into the social space. This influenced not only the development of professional needs, but also gradually improved students' social image.

Changes in socio-cultural environment during Modern era (increased significance of education, secularization, development of science, pragmatism and rationalization of livelihood, transformation of social connections), in general, reflected on students' way of life and became demonstrative for discovering student youth's social mission. University education expands along with establishment of nation-states, therefore, it is connected with their needs. According to scholars, the unifying function of universities and development of national culture in them weakened during XVI - XVII centuries. But traditional forms of organizing scientific and learning activities, as well as social communication system are replicated at every national university (Zhukovska, 2011; Litoshenko, 2004). Thus, traditions and innovations coexist without obstructing each other. Students' social mission accentuated the transition from religious to professional civic priorities, which was also notable in the educational process (improved methods and forms of teaching).

At the beginning of XIX century the university system was reformed, with Humboldt's ideal of "science university" reformulating the old "idea of university" - universities owe nothing to the government, it is the other way around - this declaration by Humboldt (1809) is well-known. For instance, Zhukovska (2011) states that "with emergence of universities at Halle (1694) and Göttingen (1737) changes in contents (researching free thinking, managing spiritual life) and methods (teaching certain science branches systematically, including students into scientific activities) of teaching students. The language of teaching also changed from Latin to native" (p. 25). Thus, German universities became the carriers of the spirit of modernity in that society, which was caused by liberalization of the science process and students' scientific activities.

Greater religious freedom and rational pragmatism of an industrial age influenced both the social values system (gradual secularization, promotion of anthropocentric axiological priorities) and the higher education system of various nation-state areas (creating national universities, priority of person's own achievements over traditional intellectual corporatism). European higher education produced content enrichment mechanisms through integration of progressive components of scientific knowledge systems, while keeping traditional humanitarian core. Such transformation influenced the dynamics of students' needs. Changes in the contents of higher education were gaining a fitting structure and organization framework. Professionalization required not only knowledge, abilities and skills, but also scientific and professional conscience and appropriate behavior models, which became the manifestation of social mission. The process of accompanying students' scientific activities, regulation of extracurricular activities and transmission of socioprofessional interests to society became more important.

Under the newest socio-cultural conditions the mission of higher education institutions and students as social subjects, who act as immediate partakers of construction of the information society, becomes especially significant. At the end of $X X^{\text {st }}$ and at the beginning of $X X I^{\text {st }}$ century scholars define the status of higher education institutions and students under conditions of information society. According to Hiddens (2004), the supranational role of universities becomes ever more significant. Contemporary universities form a certain "cosmopolitan" generation that 
plays a key role in future development of Europe, particularly when it comes to studying cultures and solving alienation issues, because regional and national cultures are put under great pressure. Moral and spiritual values, which traditionally served as a backbone of society, are also threatened. Thus, the higher education institution and the subjects that partake in teaching and education process become a community, which according to the results of joint activities not only holds on to the value and education level that is required in a new information reality, but also facilitates the activation of creative potential. Among general global integration processes it is exactly higher education that must take up an important mission: to train professionals with creative and extraordinary approaches to improving various components of professional social reality.

One characteristic feature of contemporary postindustrial society is that a global information space is being created, which brings the quality of life to a new level; increases the proportion of information and communication technologies; qualitatively new communication tools and means of effective information interaction between people appear to be based on the increasing access to national and worldwide information resources; a need to satisfy the growing human needs for information products and services arises. Under conditions of global human culture construction, a higher education institution and students as a social subject must play a role of pioneers in the process of preserving cultural identity of various peoples and promotion of national and state communities to victimless global integration on the basis of entire humanity's values. Ortega $y$ Gasset (2005) warns against becoming "a person of masses", meaning against rejection of effort to create personal life and turning into a "civilized barbarian" - a narrow-minded specialist, unable to complete the task of a generation according to the demands of the age - as a result of studies. This means that the culture is always broader than professional growth and inclusion into cultural values is a context of higher education and one of its main tasks in contemporary information society.

Expansion of information space is dynamic, but mostly chaotic, which increases the importance of democratic, particularly, didactic mechanisms of regulating its influence on various aspects of students' livelihoods. In our country, a definitive trait of a higher education system is that it aims at completion of three responsible tasks simultaneously - to facilitate reconstruction of a nation-state, to integrate into European community, to become a subject of information society construction without losing its own identity and culture. Thus, contemporary higher education institution concentrates these obligations within itself, remaining within an establishing information society and nullifies the borders between education and socio-cultural space, making it more open than before, which requires a proper improvement of the aim, tasks, methods and forms of organizing the education process. This is what makes student youth, who are an equal subject of this socio-creative activity, take up, aside from traditional tasks, a mission of integrating into the post-industrial society and the leading social role of a creative leader. This affects both the key factors of contemporary students' social mission development and the organization of educational teaching process of a higher education institution.

When researching the contemporary tendencies of higher education development in Ukraine and new requirements for the quality of teaching, professionals make new demands regarding professional qualities that make up the components of students' social mission. Innovational knowledge person can exist in terms of rapid social transformations, a self-sufficient democratic person will conduct further changes, and "under conditions of globalization, civic unity, national cohesion and, as follows, patriotic education of youth not only remains significant, but also remains essentially a strategic task" (Kremen, 2013, p. 50).

The challenges of today cause changes in the training system, which, on the one hand, must preserve the best traditions of teaching student youth, and, on the other hand, flexibly use new optimization technologies in higher educational process. The latter is defined by the Ukrainian education law as a system of scientific, methodological and pedagogical measures, aimed at personal development through the formation of its competences (The Law of Ukraine "On Education", 2017).

An experienced professional must not only possess mastery, but also be socially responsible for hislher own acts within a chosen profession. Dubaseniuk (2011) stresses the significance of generalized tendencies of higher education system's development. Contemporary demands of worldwide and Eurointegration transformations should be taken into account during planning and 
organization of the educational process and the "reconstruction of educational process, aimed at making learning creative and able to lay a foundation for scientific research and project construction; improving differentiation and individualization of an education process; implementing the principles of lifelong learning; active search for a new methodological system must be considered" (Dubaseniuk, 2011, pp. 138-139).

Bystrova (2015) describes the details of new approaches to organizing teaching and draws attention to the fact that "a creative component of education gains more significance, all the participants of the educational process become involved, students' creative search independence becomes stronger, the concepts of problem and interaction teaching, which are related to the usage of computer systems, have become especially significant" (p. 29). According to the author, "contemporary education content must navigate towards using information technologies, spreading interactive, electronic teaching with access to digital resources and intellectual teaching for the future" (Bystrova, 2015, p. 30). Obviously, innovational changes in higher education must be accompanied by combined systematic restructuring in teaching and education.

After generalizing researchers' positions regarding the significance of students' social mission because of transformation processes and their correlation with new quality demands for the education process, we may conclude that:

Firstly, a higher education institution becomes a creative environment for forming universal and professional competencies and development of social values and traits for students, which makes it necessary to rebuild the foundations of organizing and managing a higher education institution as an open system, particularly in accordance with the Law "On Higher Education", article 26 , which states the following tasks are of highest priority: conducting education on a high level of quality, conducting scientific activities by means of research and facilitating the creative activities of those who partake in the education process; forming personality through patriotic, legal, moral and ecological education, social activeness, civic position and responsibility; preservation and multiplication of moral, cultural and scientific values and achievements of society; spreading knowledge across the populace, increasing educational and cultural level of citizens, etc. (The Law of Ukraine "On Higher Education", 2014).

Secondly, reviewing the contents of curriculum and programs in order to modernize them according to the demands of contemporary science, particularly designing an optional course in the field of humanitarian disciplines, which enables formation of not only strong systematic knowledge basis for a person, but also of developed value awareness of one's own professional activity in new socio-cultural terms (Nahaiev, 2007), and transmission of positive socio-professional behavior models in an open information society.

Thirdly, the mission of a pedagogue at a higher educational institution as "mediation between students and a system of ideas, traditions and culture of people and humanity" must be realized, in order to "educate worthy people that are capable of enriching the heritage of humanity" (Kozlova, 2015 , p. 45), a contemporary teacher must always look for new creative interaction forms to use with students, while also scientifically improving the contents and methods of teaching at an institution. This forms teacher's responsibility for not only knowledge transmission, but also for forming a worthy person through cooperation with a student.

Fourthly, implementing new authorial forms and methods of teaching and studying (information and communication technologies, virtual, distance, training, game and others) into the educational process that would be favored by students where they might participate as an active subject might make the process of education more flexible and variable in terms of a single strategic direction of training a future professional. The proportion of interactive teaching methods for leading theoretical ideas will increase, proper practical preparation will be conducted, and student participation in generating new knowledge will deepen, which will decrease the number of instances of such as sad to acknowledge, a widespread thing among students as plagiarism and muss unjustified information borrowing (Palfrey et al., 2009).

Fifthly, operative methodological accompaniments of teachers in dynamic conditions of rebuilding the higher education system will enable direction and optimization of improving teaching under conditions of information society and Eurointegration. For instance, coordination with today's transformation processes (globalization in various fields, Ukraine's steady development concept) 
and further implementation of integration into international and European education (foreign language, academic mobility) require constant professional methodologists' attention. Thus, increases the significance of teachers' constant methodological training to use innovative and interactive teaching methods.

Sixthly, in terms of professional's practical training closeness to real practical conditions of future profession is necessary. Implementing a supervision institute on practicum bases will enable constant feedback from an education institution and operative correction of practical tasks. Auditorium practical training must be realized by implementing interactive imitation tasks (role play, business games, case method, brainstorming, etc.), which will facilitate the development of students' social creativity (Allwood \& Selart, 2010).

Seventhly, it is necessary to use system innovation in extracurricular activities of an education institution, which strongly affects the social mission of contemporary students, and helps actualize the educational environment for the sake of revealing students' creativity. As percentage of information consulting services, particularly the remote services, raises nowadays, the need for new technologies and communication tools that enable both teachers and students to interact with people of other ages and social status increases. This will facilitate the transmission of socially positive behavior models, for example, in order to prevent the spread of ageism (discrimination by age) and involvement of student youth into socially-positive activities (civic activities, volunteering) as both initiators and subjects. Not only tasks and contents of consulting will change, but also its forms. Traditional higher educational institution consulting (councils, methodological seminars, consultations and others) will be replaced by new and interactive ones (Internet conference, theme blog, intellectual enlightenment training, heuristic quest and others), new work forms will be used, which can be borrowed from other kinds of professional activities (peer-to-peer technology, working in an open social environment of a territorial community).

\section{Results}

Empirical verification of the statements proposed was conducted via the pilot experiment in terms of master research (Dudko, 2017) under the guidance of this article's author. An online survey was conducted with the assistance of education quality assurance and innovational development department, as well as electronic education tools department, among the $4^{\text {th }}$ year students at Simon Kuznets Kharkiv National University of Economics (further in the text - KhNUE) regarding their satisfaction with the quality of educational process. Its contents reflect some points regarding the improvement of the educational process at higher educational institutions in contemporary conditions and are fundamental for further design of a diagnostic toolset.

An online questionnaire method was used due to its significant advantages and additional options, like saving resources, larger data samples, speed of questioning, ability to respond instantly, breadth of coverage, organizational flexibility, etc.

Students were offered 23 questions in total, which were divided into groups (thematic blocks) that ensured consistency and logical placement: "Subject teaching"; "Evaluation and feedback"; "Academic support"; "Study resource for a subject"; "Personal development"; "General impression". According to the structure of the online questionnaire questions are divided into two groups: unlimited - these are the questions that students could answer in a form they themselves choose (no options were offered, a responded could express him- or herself freely); limited - a complete list of answer options was offered, only one was meant to be chosen.

Responses to questions were graded as: "Completely agree"; "Mostly agree"; "Might agree, might not agree", "Mostly do not agree", "Completely do not agree"; "Never used". When calculating the results of the survey, positive responses "Completely agree" and "Mostly agree" were taken into account. The acquired positive responses were compared to the number of respondents in terms of percentage. The survey was anonymous, meaning that every student had a chance to answer the questions of the survey without the influence of fear.

According to the results of an online survey "Satisfaction with the quality of the education process", the research data sample consisted of 228 students' answers from the $4^{\text {th }}$ full-time course (see Figure 1). 


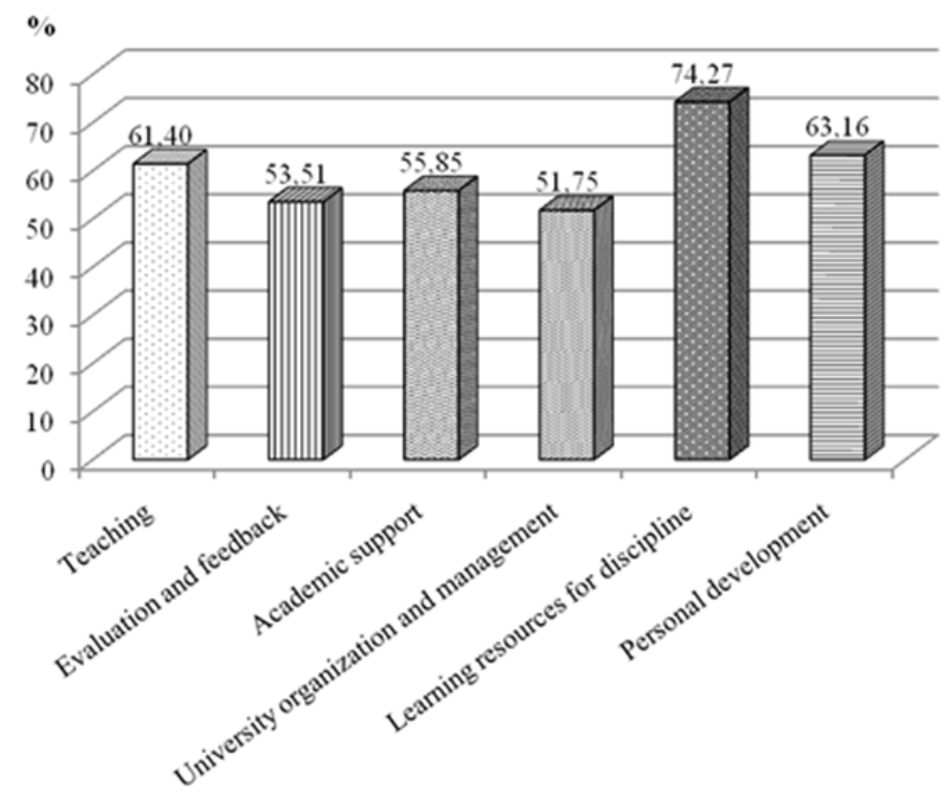

Figure 1. Students' evaluation of satisfaction with the quality of the education process

Most of the students that undertook the survey $(61,40 \%)$ think that teaching at KhNUE is satisfactory and teachers approach teaching and treatment of students responsibly. This is confirmed by the results of the theme block "Personal development" $(74,27 \%)$, which confirms the fact that the interaction between participants of the education process is productive.

However, not all students $(53,51 \%)$ were able to understand the evaluation system and were not informed enough about the acquired grades and subject evaluation criteria. This is also the evaluation level of university organization and management $(51,75 \%)$. According to the students $(55,85 \%)$, academic support functions within university, but leaves much to be desired.

Analysis and grouping of students' answers to open questions about the advantages and disadvantages of teaching process organization allowed us to highlight the common positive and negative aspects (Table 1).

Table 1. The advantages and disadvantages of teaching process organization at KhNUE

\begin{tabular}{|l|l|}
\hline Advantages & Disadvantages \\
\hline $\begin{array}{l}\text { Lecturers teach discipline and explain the } \\
\text { material well. }\end{array}$ & $\begin{array}{l}\text { Low level of stimulation to study discipline by using of } \\
\text { intellectually directed tasks. }\end{array}$ \\
\hline Lecturers give advice to students. & $\begin{array}{l}\text { The teachers do not fully use the means of teaching process } \\
\text { organization for motivation students to study the discipline. }\end{array}$ \\
\hline $\begin{array}{l}\text { The opportunity for students to use the library } \\
\text { and electronic resources of the university. }\end{array}$ & $\begin{array}{l}\text { The lack of proper explanation about the evaluation criteria of } \\
\text { the discipline. }\end{array}$ \\
\hline $\begin{array}{l}\text { Gaining confidence after studying the } \\
\text { discipline. }\end{array}$ & The lack of sufficient mobility of students. \\
\hline
\end{tabular}

After analyzing the answers, it is possible to formulate the following recommendations for improvement of teaching process organization: ensure greater student mobility and a flexible study schedule, for example distance learning was proposed for some subjects; increase the number of practical tasks, material, correlation of theory with today, praxis of real businesses and well-known companies; design and implementation of modern methods and tools to conduct lessons 
(interactive boards, modern software etc.); change of evaluation criteria, obligatory familiarization of student with evaluation system; organization of interesting events and training session for students.

\section{Conclusions}

Thus, transformation of higher education system causes the manifestation of culture-making foundation of higher education, particularly students' social mission in the culture of humanity. Throughout the phylogeny from the social role of a philosopher and theologist, through the development of profession-oriented needs and civic activity, partaking in voluntary social service, voluntary support of various social groups and projects, today the ideal of a creative social leader that transmits the new social behavior models and embodies the vanguard of progressive social ideas is crystallizing. It is necessary to implement new organization and management conditions within the higher education institutions, review and modernize curriculum and programs, implement new methods and forms of teaching and learning, deepen practical training, implement systematic changes in extracurricular work to manifest student youth's social mission. Empiric research that was conducted in order to evaluate the quality of the education process by students as its subjects provided us with the following facts: most students that were questioned believe that subject are being taught on a satisfactory level, teachers treat lesson conduct and students with respect, however not all students understood the subject evaluation system, academic support is functional, but requires improvement. Future research will include production of scientific proposals to systemize the changes in the education process, taking into account contemporary transformation tendencies and demands for development of a competent professional and creative social leader.

\section{References}

Allwood, C.M., \& Selart M. (2010). Decision Making: Social and Creative Dimensions (pp. 35-51). Kluwer Academic Publishers.

Bystrova, Y. (2015). Innovative methods of teaching in the higher school of Ukraine. Law and Innovative Society, 1 (4), 230, 27-33.

Drach, O. (2014). Educators of the people: the social mission of graduates of the highest female courses of the Russian Empire. Ukrainian peasant. 14, 247, 66-69.

Dubaseniuk, O.A. (2011). Development of Higher Education: Trends and Prospects. Man-centerism as the basis of the humanitarian policy of Ukraine: education, politics, economy, culture. GChl of the NAofPS of Ukraine, 135-142.

Dudko, N.V. (2017). Features of the educational process in higher education in terms of transformation of education. Unpublished master's thesis, Simon Kuznets Kharkiv National University of Economics, Kharkiv, Ukraine.

Hiddens, A. (2004). Runaway World: How Globalization is Reshaping Our Lives. Moscow: Ves' Mir.

Humboldt, W. von (1809). Über die innere und äussere Organisation der höheren wissenschaftlichen Anstalten in Berlin [On the internal and external organization of the higher scientific institutions in Berlin]. Reprinted in A. Flitner \& K. Giel (Red.) (1960-81), Werke in Fuenf Baenden, Band IV, Schriften zur Politik und zum Bildungswesen. Stuttgart: J.G. Cotta.

John Palfrey, Urs Gasser, Miriam Simun, \& Rosalie Fay Barnes. (2009). Youth, Creativity, and Copyright in the Digital Age. Int'l J. Learning \& Media. [Online] Available: http://nrs.harvard.edu/urn3:HUL.InstRepos:3128762.

Kozlova, G.M. (2014). Teaching Methods in Higher Education. Odessa: ONUofE, rotaprint.

Kremen, V.G. (2013). Quality education and new time requirements. In V.O. Ohneviuk \& S.O. Sysoeva (Eds.), Education: textbook, p. 45-50.

Litoshenko, D. (2004). Evolution of university education in Europe XVI - the end of XVIII centuries. Vladivostok.

Nahaiev, V.M. (2007). Methods of teaching in higher education. Kyiv.

Ortega y Gasset, J. (2005). University Mission. Minsk: BGU.

Orzhel, O. (2017). University Social Responsibility in the Context of University Leadership. Kyiv: DP «NVC» «Priorytety».

Shevchuk, S., \& Shevchuk, O. (2013). Corporate social responsibility through the eyes of students. Actual problems of training and education of people with special needs. 10, 346, 74-85.

The Law of Ukraine "On Education" (2017). Retrieved June 1, 2018. [Online] Available: http://zakon5.rada.gov.ua/laws/show/2145-19. 
The Law of Ukraine "On Higher Education" (2014). Retrieved June 1, 2018. [Online] Available: http://zakon3.rada.gov.ua/laws/show/1556-18.

Ulisses Ferreira de Araújo, Valéria Amorim Arantes, Ana Maria Klein, \& Patrícia J. Grandino. (2014). Youth purpose and life goals of students engaged in community and social activities. Revista Internacional d'Humanitats, 30, 128, 119-128.

Uvarov, P.U. (Producer). (2013). Medieval University [Motion picture]. [Online] Available: http//postnauka.ru/video/11353.

Vynoslavcka, O., \& Kovalchuk, O. (2011). Social responsibility in engineering as an important area of training specialists in technical universities. The Legal Bulletin of the University "KROK". Psychological Sciences, 7, 101, 72-77.

Zhukovskaia, T.N. (2011). Universities and university traditions in Russia. Petrozavodsk: Publishing house PetrSU. 